
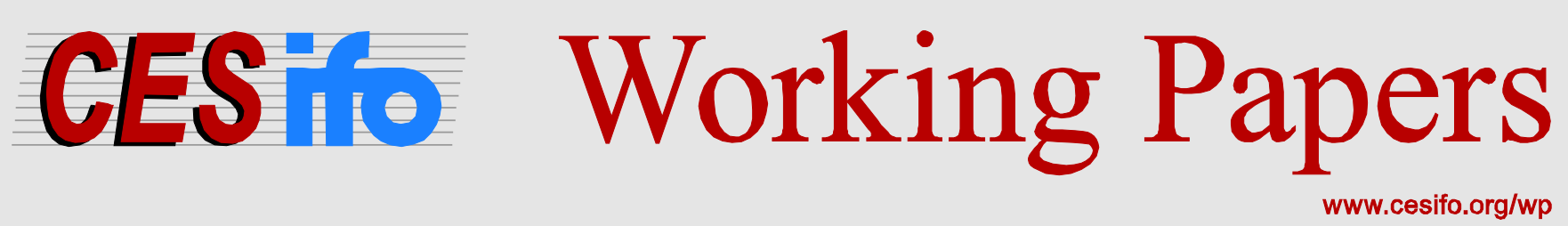

\title{
Complex Financial Networks and Systemic Risk: A Review
}

\author{
Spiros Bougheas \\ Alan Kirman
}

\author{
CESIFO WORKING PAPER NO. 4756 \\ CATEGORY 7: MONETARY POLICY AND INTERNATIONAL FINANCE \\ APRIL 2014
}

An electronic version of the paper may be downloaded

- from the SSRN website:

- from the RePEc website:

- from the CESifo website:

wWW.SSRN.com

Www.RePEc.org

www.CESifo-group.org/wp

\section{CESifo}




\title{
Complex Financial Networks and Systemic Risk: A Review
}

\begin{abstract}
In this paper we review recent advances in financial economics in relation to the measurement of systemic risk. We start by reviewing studies that apply traditional measures of risk to financial institutions. However, the main focus of the review is on studies that use network analysis paying special attention to those that apply complex analysis techniques. Applications of these techniques for the analysis and pricing of systemic risk has already provided significant benefits at least at the conceptual level but it also looks very promising from a practical point of view.
\end{abstract}

JEL-Code: D850, G200.

Keywords: complex financial systems, networks, systemic risk.

\author{
Spiros Bougheas* \\ School of Economics \\ University of Notthingham \\ United Kingdom - NG7 2RD Nottingham \\ spiros.bougheas@nottingham.ac.uk
}

\author{
Alan Kirman \\ GREQAM, EHESS \\ Aix-Marseille University \\ France \\ alan.kirman@univ-amu.fr
}

*corresponding author 


\section{Introduction}

The 2007-2009 global financial crisis has painfully demonstrated how costly a systemic failure can be. Systemic events impose high costs on taxpayers as governments usually intervene by bailing out important institutions in an effort to ensure the survival of the financial system. Unfortunately, the implementation of such policies are also part of the causes of the next crisis. This is because they encourage opportunistic behavior by these same institutions in anticipation of the government policies. This "moral hazard" problem is central to understanding the dilemma with which policy makers are faced.

The study of financial crises has been on the research agenda of financial economists for a long time now. ${ }^{1}$ One particular aspect of systemic crises that has recently attracted a lot of attention is that of contagion. Even if an initial shock affects only a small number of institutions, the connectivity of the financial system (for example, because of the interbank market, the payments system, portfolio correlations. etc.) implies that the shock will be transmitted widely, and will increasingly often cross international boundaries. ${ }^{2}$ Some researchers have applied the tools of network theory, that is ideally suitable for the analysis of interconnected systems, to the study of systemic events. ${ }^{3}$ What becomes clear from this work is that both the number of affected institutions and the financial system's volume of losses depend not only on the aggregate volume of risk exposures but also on their distribution within the system and the structure of that system. ${ }^{4}$

Simple models are very useful for providing a conceptual framework so that we can gain an intuitive understanding of the relationship between network structure and systemic risk. However, they fall short of providing practical guidance to regulators and policymakers in relation to actual financial networks that consist of a large number on institutions with a huge number of links between them. What we need are tools for the study of such systems so that we can get better estimates of both the likelihood of contagion and systemic risk. The ecologist Robert May has been a strong advocate of the application of complex systems analysis to the study of financial networks. ${ }^{5}$ Over the last 10 years, many researchers have followed this promising line of research by using these analytical tools to improve our understanding of the financial sector in general and banking systems in particular. ${ }^{6}$ In this paper, we review this new and fast growing literature paying special attention to issues related to the measurement of systemic risk. In the following section we review various proposals for measuring systemic risk that use traditional finance tools. In the subsequent two sections we review theoretical and empirical contributions that employ complex networks techniques to the analysis of systemic risk. In the

\footnotetext{
${ }^{1}$ See Brunnermeier and Oehmke (2012) for a review of this literature.

${ }^{2}$ For an interesting exposition of the geographic distribution of bank failures during the recent global financial crisis see Aubuchon and Wheelock (2010).

${ }^{3}$ For expositions of network theory and its applications to economics see Goyal (2009), Jackson (2008) and Vega-Redondo (2007) .

${ }^{4}$ See Allen and Babus (2009) for a review of various applications of network theory to the study of financial issues.

${ }^{5}$ See, for example, Haldane and May (2011) and May and Sugihara (2008). For a similar perspective on the benefits of network analysis, see also Schweitzer et al. (2009).

${ }^{6}$ There is an established literature, known as econophysics, that has used complex systems to analyze various economic systems icluding the behavior of asset prices (for a review see Varela et al. (2013) this volume).
} 
final section we briefly evaluate the progress that has been made so far and identify areas for further research.

\section{Non-Network Approaches to Measuring Sys- temic Risk}

Since the 2007-2009 global financial great emphasis has been placed on developing both theoretical and practical measures of systemic risk. ${ }^{7}$ Some researchers have opted for a structural approach while others have worked with reducedform approaches that focus on the behavior of asset returns in the tail of the distribution. The structural approach requires a general equilibrium model and explicit restrictions on structural errors so that the parameters of behavioral functions can be estimated. In contrast, the goal of reduced-form studies is to provide estimates for these parameters using exogenous within-sample variation minimizing the reliance on structural assumptions.

The structural approach is followed by Gray et al. (2008) who propose the use of Contingent Claims Analysis (CCA) to evaluate the sensitivity of an economic system's balance sheets to external shocks. CCA treats risky debt, which raises the possibility of default and thus systemic risk, as a put option. ${ }^{8}$ If one type of risky debt (loans from banks to firms) is linked to another type of risky debt (loans from banks to banks), the second type of risky debt can be expressed as a function of the implicit put option of the first type of risky debt. Strong non-linearities in risk transmission can potentially arise from this compound nature of interlinked risky debt. ${ }^{9}$

Segoviano and Goodhart (2009) view the banking system as a portfolio of banks from which they infer the banking system's multivariate density. Their measures reflect not only linear dependencies within the system (correlations) but also non-linear distress dependencies that alter through time. Employing a non-parametric copula approach they are able to distinguish between (a) common distress in the system, (b) distress between specific banks, and (c) cascade effects. They use their approach to derive a variety of bank stability measures and then use them to estimate changes in the stability of the US banking system over time, to estimate cross-regional effects between American and European banking groups and to assess the impact of international banks on sovereigns.

One advantage of the structural approach is that it allows one to derive consistent measures for the marginal risk contribution of each institution in the system. These measures are consistent in the sense that they add up to the aggregate systemic risk. This has been the motivation behind the work by Tarashev et al. (2010) who use a game-theoretic methodology to apportion system-wide risk to individual institutions. In particular, they use the Shapley Value (a solution for cooperative games) that allocates payoffs to players that

\footnotetext{
${ }^{7}$ For a review of systemic risk measures applied to general financial systems see Markeloff et al. (2012). See also European Central Bank (2007) for some theoretical and empirical contributions related to the measuremnt of systemic risk in banking and non-banking financial systems.

${ }^{8} \mathrm{~A}$ put option is a derivative that offers the right, but not the obligation, to the holder to sell the underlying asset at a pre-specified price within a given period.

${ }^{9}$ For an example of CCA see Lehar (2005) who applies the methodology to a sample of international banks from 1988 until 2002.
} 
are equal to their marginal contributions. The idea is simple but appealing. The marginal contribution to risk of an institution to a group of banks is the amount by which the aggregate risk of the group increases when that bank is added. Consider all the possible groups of banks and evaluate the marginal contribution of the particular bank to each of them. The overall contribution to risk of the bank in question is then a weighed sum of all these marginal contributions. Huang et al. (2012) also construct systemic risk measures satisfying consistency, but use a different approach. They use equity-price comovements and Credit Default Swap $(\mathrm{CDS})^{10}$ spreads to construct hypothetical insurance premiums against catastrophic losses in the banking system. The first factor provides a measure of asset return correlations while the second measures the probability of default. Applying their methodology to the US banking system the authors find that a bank's systemic risk contribution is primarily determined by its size and to a lesser extent by the correlation of asset returns and default probability.

CDS prices are also used, together with bond prices, by Giglio (2011) who develops an alternative method for measuring joint default risk of large financial institutions. Bond prices offer information about the default probability of the issuer while CDS prices, that pay only if the seller of the insurance contract is solvent, contain information about the probability of joint default. This allows one to derive pairwise default probabilities within the financial system. However, it is not sufficient to characterize the systemic risk (joint default risk) of multiple institutions. Then, the author develops a general theory of probability bounds that permits the construction of tightest bounds for probabilities of high-order events given the availability of a low-order information set. The author applies the methodology to follow the evolution of default risk of large banks during the 2007-2009 financial crisis and finds that the majority of spikes in bond and CDS prices corresponded to changes in idiosyncratic rather than systemic risk.

Turning now to the studies that focus on the tail of the return distribution, Acharya et al. (2010) derive a theoretical measure of systemic risk, namely the Systemic Expected Shortfall (SES) which is equal to the expected amount that a bank is undercapitalized in a future systemic event in which the overall financial system is undercapitalized. Their theory suggests that the regulation of systemic risk should depend on each institution's SES and the overall probability of a systemic event. For practical purposes regulators need to estimate the conditional expected losses before a crisis occurs and according to the theory they should use any variable that is a good predictor of capital shortfall during a systemic event. They propose that the regulators estimate the Marginal Expected Shortfall (MES) that corresponds to the amount of expected losses during moderately bad days together with the level of leverage as predictors for SES. The authors use data from 2007-2009 during the financial crisis to demonstrate that their measure of systemic risk would have been a good predictor of subsequent measures of risks, such as outcomes of stress tests, the decline in equity evaluations, and the widening of credit default swap spreads.

Hartmann et al. (2005) apply Extreme Value Theory (EVT) on bank equity prices which allows them to estimate the probability of contagion between banks, the sensitivity of banks asset returns to aggregate shocks and also the fluctuations of those risks over time. In particular, they construct two indicators

\footnotetext{
${ }^{10} \mathrm{~A}$ CDS is a financial swap agreement whereby the seller of the contract will compensate the buyer in the event of a loan default. The buyer of the CDS makes a series of payments to the seller but only receives a payoff if the loan defaults.
} 
of systemic risk. The first indicator captures bank contagion risk by measuring extreme comovements of bank asset returns. The second indicator captures the impact of aggregate portfolio shocks on individual banks' stock returns. The authors apply their methodology to US and European banking systems finding that while systemic risk has increased in both regions during the 1990s, systemic risk is higher in the US than in the Euro area, probably due to the weaker cross-border European banking linkages relative to U.S. ones. ${ }^{11}$

Value at risk (VaR) is a common measure of risk used by financial institutions. For example the $5 \%$-VaR is the maximum loss within the $5 \%$ confidence interval. Clearly, a single institution's measure of risk cannot reflect systemic aspects of risk. Adrian and Brunnermeier (2011) propose an alternative measure that they refer to as CoVaR. An institution's CoVaR is equal to the VaR of the whole system conditional on that institution being in a particular state (distress or no-distress). By taking the difference between the CoVaR conditional on the institution being in distress minus the CoVaR conditional on the institution not being in distress the authors derive $\Delta \mathrm{CoVaR}$ that captures the marginal contribution of that particular institution to systemic risk. However, from a regulatory point of view what is needed is a forward looking measure that would be a good predictor of future systemic events. To this end, the authors estimate forward looking time-varying measures of $\Delta \mathrm{CoVaR}$ using weekly data from 1986Q1 to 2010Q4 and show that the 2006Q4 value would have predicted over half of realized covariances during the global financial crisis. ${ }^{12}$

More closely related to the network literature, Billio et al. (2012) derive econometric measures of the degree of connectedness, and hence systemic risk, for four financial sectors, namely, hedge funds, banks, brokers, and insurance companies. They use principal-components analysis to uncover the degree of connectedness among the institutions in the four sectors and then they apply Granger causality tests in order to identify the direction of links. Their results suggest that among the four sectors the most important in transmitting shocks is the banking sector.

\section{Systemic Risk in Complex Financial Networks: Theoretical Developments}

There is a steadily increasing literature suggesting that our understanding of systemic risk, and hence our ability to measure it, will be greatly enhanced by taking a close look at the topological properties of the network of transactions that link financial institutions together. ${ }^{13}$ A typical financial network can be graphically represented by a set of nodes, one for each institution, and a set of weighted and directed links representing the bilateral financial relationships between those institutions. Depending on the application these values can measure either financial exposures (e.g. interbank deposits) or financial transactions (e.g. interbank payments market) over a period of time. Figure 1 shows the

\footnotetext{
${ }^{11}$ The second indicator, known as Tail- $\beta$, has been also applied to the European banking system by De Jonghe (2010).

${ }^{12}$ Applications of this methodology include Wong and Fong (2010) who provide CoVaR estimates for the CDS of Asia-Pacific Banks and Gauthier et al. (2009) who give systemic risk estimates for the Canadian banking system.

${ }^{13}$ For a more thorough exposition of network theory see Varela et al. (2013) in this volume.
} 
Bank 1

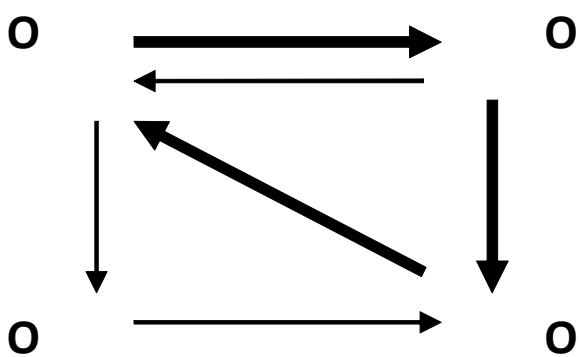

Bank 2

$\mathbf{0}$

$\mathbf{0}$

Bank 3

Bank 4

Figure 1: A 4-Bank Network

graph of a 4-bank network where a link connecting bank $i$ with bank $j$ and with the arrow pointing to bank $j$ represents the deposits of bank $i$ at bank $j$. The thicker the arrow, the higher the weight of the link, that is the level of deposits. Thus, the graph captures the level of bilateral exposures.

The graph of a network of $n$ banks can also be presented by a $n \times n$ realvalued matrix $A$. An entry $\alpha_{i j}$ represents the level of deposits of bank $i$ at bank $j$. For example, a matrix corresponding to the network shown in Figure 1 is given by

$$
A=\left(\begin{array}{cccc}
0 & 100 & 50 & 0 \\
50 & 0 & 0 & 100 \\
0 & 0 & 0 & 50 \\
100 & 0 & 0 & 0
\end{array}\right)
$$

Notice that along the diagonal all entries are equal to 0 capturing the fact that a bank does not hold deposits with itself. To keep things simple we have considered only three possible levels of exposure. In the above matrix entry $\alpha_{12}=100$ which corresponds, in Figure 1, to the high weighted arrow connecting bank 1 with bank 2 and pointing at bank 2 and indicating that bank 1's level of deposits at bank 2 is equal to 100 .

As we explain in more detail below, introducing a shock into the system is equivalent to disturbing some of these links. Analyzing the systemic consequences of that shock involves not only tracing the path of links that connects the institution where the shock was realized with the rest of the system but also taking into consideration their weights. In what follows we focus on research related to the analysis of banking systems, starting with simple networks and 
then moving to complex ones. ${ }^{14}$

\subsection{Simple Banking Networks}

This literature builds on some earlier work on interbank relationships that explores the negative externality that a failure of one bank imposes on the rest of the system; see, in particular, Bitzer and DeMarzo (1992) and Rochet and Tirole (1996). The main contribution of the following papers is the recognition that in a multi-banking system the specific link pattern of the network matters.

For example, Allen and Gale (2000) analyze the transmission of liquidity shocks within a four-bank network where the role of each bank is to provide liquidity insurance as in the Diamond and Dybvig (1983) and Allen and Gale (1998). ${ }^{15}$ The authors find that the systemic impact of an initial shock crucially depends on the structure of the network. When all banks are interconnected to each other, that is the structure of the network is complete, then cross-holding of liquidity can be sufficient to absorb the shock without banks having to liquidate long-term assets. In contrast, when the structure is incomplete, the impact of the shock might be felt very strongly by banks immediately linked to the one that suffered the initial shock resulting in the liquidation of their long-term assets. As each subsequent link is affected the crisis spreads throughout the system.

Allen and Babus (2010) compare the systemic risk consequences of two network structures each consisting of six banks. In both structures each bank forms links with two other banks. In one structure, which the authors call clustered, there are two networks each consisting of three banks. In the unclustered version there is a single network with a cyclical structure. The authors concentrate their analysis on the case of short-term debt that requires rollover between periods and hence raises the possibility of systemic risk. For risk diversification purposes banks exchange assets within their network. The exchange of assets implies that under the clustered structure banks hold identical portfolios while this is not the case in the unclustered version. The authors find that the likelihood of early liquidation and thus systemic risk is higher in the clustered version but, if the proceeds from early liquidation are sufficiently high, the welfare of depositors can still be greater under the clustered structure.

Leitner (2005) takes one step back by asking if having a network offers any advantages. The author compares a complete network with one where every node is isolated and finds a trade-off. On one hand, there are insurance benefits due to the cross-links between banks but, on the other hand, this also raises the possibility of the whole network collapsing. Furthermore, when liquidity is concentrated in a small number of institutions the latter might opt not to participate. Similarly, Castiglionesi and Navarro (2007) find that the network structure depends on the level of counterparty risk. The network is generally characterized by a core-periphery structure where the core consists of safe banks that are fully connected but the degree of connectivity between the core and

\footnotetext{
${ }^{14}$ Other researchers use complex analysis for understanding interfirm financial (trade-credit chains) networks; see Battiston et al. (2007), Cossin and Schellhorn (2007), Kiyotaki and Moore (2004) and Lagunoff and Schreft (2001).

${ }^{15}$ The two-bank version of the Diamond and Dybvig (1983) is analyzed by Bhattacharya and Gale (1987), however, a minimum of three banks are needed for comparisons of network structures to become meaningful.
} 
the periphery (risky banks) depends on the level of counterparty risk. Issues related to network formation are also addressed by Babus (2009). In this model network formation is endogenous and the author shows that the optimal network structure is stable and reduces the risk of contagion.

\subsection{Complex Banking Networks}

A bank or a group of banks, can be potentially affected by two types of shocks. A sudden strong demand for liquidity can force the banks, after they exhaust their reserves, to use their deposits at other banks. This can initiate a domino effect that, depending on the network structure, can spread throughout the system. As long as there are enough liquid assets in the system, interbank deposits might be sufficient to absorb the demand for liquidity. However, if for some banks their deposits in the rest of the system are not sufficient to meet the demand for liquidity they might have to liquidate some of their long-term assets. If selling those assets depresses their prices this can lead to insolvency which is related to the second type of shock that is a direct hit on the asset side of the balance-sheet. In this case a bank has to write-off a significant fraction of its long-term assets mainly caused by the inability of its borrowers to pay back their debts. The theoretical literature that uses complex network techniques to address issues of contagion focuses on the systemic risk consequences of the second type of shock.

Caballero and Simsek (2009) analyse information transmission in a cyclical network structure where each bank is directly informed about its risk exposure to its neighbors. While most of the time this structure is sufficiently stable, in periods of high financial distress, when each bank becomes interested in its exposure to other banks through indirect links, the cost of information gathering becomes unmanageable and an financial crisis ensues. In a related study Anand et al. (2011) use a mean-field approximation to analyse how banks can coordinate on a strategy which can lead to inefficient information aggregation and can then switch to coordinate on another strategy in which all information is revealed and the market crashes.

Many authors examine how network connectivity is related to systemic risk. Iori et al. (2006) find that when the network of banks is heterogenous, an interbank market can have ambiguous consequences for systemic risk. The benefits of mutual insurance need to be contrasted to the possibility of contagion. The authors also report that as the connectivity increases the system becomes more stable, echoing the finding of Allen and Gale (1998). Similar conclusions in relation to the degree of network connectivity are reached by Gai and Kapadia (2010), Montagna and Lux (2013) and Nier et al. (2007). The former paper also compares the impacts of indiosyncratic and aggregate shocks. With relatively high capital to total assets ratios the system can survive the former type of shock but with aggregate shocks contagion risk significantly increases. Montagna and Lux (2013) analyse scale-free networks while the other papers focus on random networks. ${ }^{16}$ A scale-free topology arises endogenously in Cruz and Lind (2012). The authors show that the distribution of 'avalanches' (systemic events) follows a power-law. In their model higher capital requirements by offering incentives to

\footnotetext{
${ }^{16}$ Random networks correspond to the classical random graphs structures introduced by Erdös and Rényi (1959).
} 
banks to increase the market concentration of the banking system can enhance the likelihood of systemic events.

Two related topics that have attracted a lot of attention in the finance literature as a result of the global financial crisis are 'fire sales' and 'market freezes'. ${ }^{17}$ Both of these issues have also been addressed using the network approach. For example, Cifuentes et al. (2005) analyse the transmission of shocks in systems that use marking to market practices. In such systems, sales of assets by depressing asset prices can induce further round of sales. The authors show that small initial shocks can generate huge systemic effects and that the exact aggregate exposure depends on the particular structure of the network. They also suggest that imposing liquidity requirements can be more effective than capital regulations in averting a crisis. May and Arinaminpathy (2010) use a mean-field approach to derive analytical results in relation to fire sales. They demonstrate how the impact of contagion depends not only on the size of the shock and the level of asset devaluation but also on the asset classes affected by the shock. Nier et al. (2007) observe that the effects of fire sales are more pronounced in higher concentrated systems. An example of a market freeze where banks decline to rollover debt is offered in Anand et al. (2012). The authors find that the spread of contagion depends on the maturity structure of loans and the rate at which adverse news spread in the system. When the endogenous probability of bank failure is sufficiently high their model also generates market freezes where banks decline to lend to each other.

Some researchers compare the impact on systemic risk of various network structures. Acemoglu et al. (2013) compare complete networks with networks that have a ring structure. They find that although complete networks are generally more stable, under extreme conditions ${ }^{18}$, the high number of interconnections can also be responsible for higher fragility. The authors also assess the welfare properties of network systems formed in a decentralized way and they find that, as banks do not internalize the negative externality that their liquidity management decisions impose on the rest of the system, overall aggregate liquidity is suboptimal. ${ }^{19}$ Contagion and cascades are analysed using variety of network structures by Elliott et al. (2013). In particular, the authors explore how changes in the degrees of integration (how far an institution depends on its counterparties) and diversification (number of counterparties) affect the spread of defaults through the system. Lenzu and Tedeschi (2012) compare systemic risk in random formed and scale-free networks. The authors find that scale-free networks are more vulnerable because of (a) sub-optimal liquidity allocation, and (b) higher heterogeneity among participants which increases the exposure of the banking system to contagion. Teteryatnikova (2012) assesses the advantages of multi-tier systems finding that the resilience of the banking network to systemic shocks increases with the level of tiering.

In an alternative application of network analysis Eisenberg and Nose (2001) develop an algorithm that not only provides an efficient way for clearing the interbank network following a shock but also provides measures of the systemic risk by each bank in the system. Their results suggest that an increase in

\footnotetext{
${ }^{17}$ For traditional finance models addressing these issues, see Acharya et al. (2011) and Diamond and Rajan (2011).

${ }^{18}$ Extreme conditions within a financial network should be understood as a systemic event, like the recent global financial crisis.

${ }^{19}$ See Castiglionesi and Navarro (2007) for a similar result.
} 
the system's cash flow volatility by reducing the payments across institutions lowers the asset value of the banking system. Lastly, more recently, Battistin et al. (2012) have proposed an alternative measue of systemic risk developed within the complex network framework which they called DebtRank. This new measure takes into account how an institution's (or a group's) financial distress impacts its counterparties across the financial network.

\section{Systemic Risk in Complex Financial Networks: Applications}

Two distinct empirical methodologies have been developed to use complex networks to analyse issues related to financial stability. One methodology uses simulations for counterfactual analysis and has been widely applied to many types of financial transactions. The other methodology analyses the topological structure of financial networks in order to assess their stability.

\subsection{Counterfactual Analysis}

One advantage of applying complex network techniques to the analysis of shock propagation is that it allows for counterfactual analysis. For example researchers can simulate the consequences of a failure of a single bank or a group of banks on the rest of the financial system. Upper (2007) provides a detailed description of the methodology.

The starting point of the analysis is the construction of the matrix $A$, described in Section 3, of bilateral exposures representing the graph of the corresponding network. Depending on the level of aggregation the nodes may represent institutions or sectors or countries. In some cases, researchers are able to use data sources that report directly bilateral exposures. However, in many applications researchers have only access to gross measures, for example, the total exposure of each institution to all other institutions. Below we reproduce matrix $A$ but now we have added the level of gross exposures.

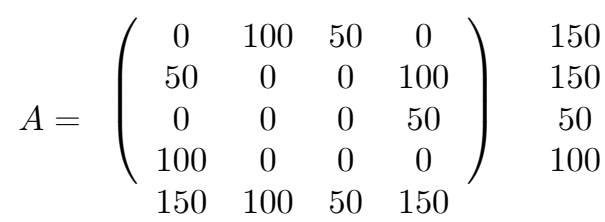

where summing across columns $\sum_{j} \alpha_{i j}$ gives the total deposits of bank $i$ at all other banks and summing across rows $\sum_{i} \alpha_{i j}$ gives the total deposits of the banking system in bank $j$. In order to obtain an estimate of bilateral exposures researchers commonly assume that an entity's assets are spread as evenly as possible given the balance sheet positions of every other entity. Technically, this amounts to the maximization of entropy of the network's linkages. Intuitively, the solution corresponds to the most likely structure of bilateral links given what the researchers know about the level of gross exposures.

Across the various studies that have followed the counterfactual approach there is considerable variation in the level of data aggregation. Below we separate them into two groups, namely, those studies in which nodes represent institutions and those that use higher levels of aggregation. 


\subsubsection{Risk Exposure at the Institutional Level}

The majority of studies that look at the network links of national interbank payments systems use simulations to assess the contagious effects of bank failures. Overall, the evidence of systemic risk is quite mixed. Substantial risk of contagion is reported by Degryse and Nguyen (2007) for Belgium, van Lelyveld and Liedorp (2006) for the Netherlands, Mistrulli (2005) for Italy, Upper and Worms (2004) for Germany, and Wells (2004) for the UK. In contrast, limited risk of contagion is reported by Blavarg and Nimander (2002) for Sweden, Elsinger et al. (2006), Lublóy (2005) for Hungary and Sheldon and Mauer (1998) for Switzerland.

Degryse and Nguyen (2007) and Mistrulli (2005) also use their data to assess how structural changes in the banking sector affect systemic risk. The banking systems of both Italy and Belgium have moved away from a relatively complete structure to one dominated by a few banks. The change in network structure seems to have increased the risk of contagion in Italy but to have reduced it in Belgium.

The studies by Angelini et al. (1996) for Italy, Amundsen and Arnt (2005) for Denmark and Furfine (2003) for USA use overnight transactions data and all three report limited possibilities of contagion.

A more general setting is analysed by Anand et al. (2012) who use UK data to calibrate a model that, in addition to links between banks, both domestic and international, also includes links between firms and banks. The authors find that the level of default rates in the corporate sector necessary to trigger a systemic failure in the financial sector is broadly comparable to the rates observed during the Great Depression and those for 2008-2009 during the current global financial crisis.

\subsection{2 'Macro' Approaches}

Closely related to the structural approach to measuring systemic risk is the work of a strand of the network literature that follows a macro methodology to analyse cross-border financial contagion. The common theme of this work is an abstraction from institutional details by focusing on sector level connections. The level of aggregation that macro approaches use for the construction of networks is significantly higher that that used in other applications.

Degryse, Elahi and Penas (2010) use data on bilateral exposures while Castrén and Kavonius (2009) and Castrén and Rancan (2013) calculate bilateral exposures from aggregate exposures by employing the methodology mentioned above. Degryse et al. (2010) analyse the propagation of shocks among the banking sectors of 17 countries on both sides of the Atlantic over the period 1999-2006. In contrast, the other two studies investigate the evolution of the financial interconnectedness of the Euro area. Castrén and Kavonius (2009) use data on financial exposures of 7 sectors at the euro area aggregate level over the period 1999-2009 while Castrén and Rancan (2013) use data for the same sectors at the country level.

All three studies strongly suggest that the network structures are timevariant, finding an increase in the number of sector links throughout the period leading to the global financial crisis of 2008-2009. The studies also conclude that factors related to the initial shock, such as geographical location, type of 
financial instrument, economic sector and country of origin, matter significantly for its potential impact both geographically and quantitatively.

\subsection{Topological Structure of Actual Financial Networks}

This literature aims to identify and analyse the network topology of the credit links between actual financial institutions. The corresponding theoretical research, reviewed above, clearly suggests that the level of systemic risk crucially depends on the particular structure of the network that includes in addition to topological properties, i.e. random, fully connected, etc., the direction and weights of its links. Empirical implementations of this approach can be very useful given that it allows researchers to identify potential systemic weaknesses in networks that involve thousands of daily transactions between a large number of institutions. However, for a long time, lack of data availability has restricted research to calibrations of theoretical models. This has changed over the last 10 years with the availability of data sets reporting real time bilateral settlements between pairs of institutions in the system. Using data from various types of financial markets located all over the world researchers have identified their corresponding topological structures. Some researchers have then used the structure revealed in this way to perform simulations aiming to identify any risk vulnerabilities within the corresponding payment system. ${ }^{20}$

\subsubsection{National Payments Systems}

For example, Boss et al. (2004) find that the structure of the Austrian interbank market network is characterized by (a) a low clustering coefficient and (b) a short average path length. This is consistent with a highly hierarchical system but as the authors observe this is in contrast to the types of network architectures usually considered in the theoretical literature. Similar conclusions are drawn by Embree and Roberts (2009) for the Canadian payments system, Lublóy (2006) for the Hungarian, Pröpper, Lelyveld and Heijmans (2012) for the Dutch system, Sokolov et al. (2012) for the Australian and Somaräki et al. (2007a) for the US Fedwire payments system. The last of these which examines the degree distribution of the network notices that overall the distribution is scale-free. A fractal structure is also identified by Inaoka et al. (2004) from Japanese banks financial transactions data. These observations have significant implications for both the likelihood of a systemic failure and the magnitude of its consequences. In particular, it is consistent with the existence of 'too big to fail' institutions that usually are positioned at the top of the hierarchy. The presence of these institutions is responsible for the 'hub and spoke' structure of the graphs of these networks which exhibit short distances between banks even when the frequency of direct relationships is low.

A hierarchical structure is exogenously imposed on the UK system. There is a two-tier system where the top consists of only 15 banks. So-called 'secondtier' banks have to settle their payments through one of the banks in the top tier. Becher et al. (2008) analyse the topological structure of the UK twotier system and compare its stability properties with those of the US system.

\footnotetext{
${ }^{20}$ For a detailed description of the methodology used to perform these simulations see Soramäki et al. (2007). There are some similarities between some of these simulation exercises and the counterfactual methodology reviewed above.
} 
The authors note that the network structures are similar in the two systems, however, they also find that there are differences in their risk characteristics. In particular, there is a trade-off where the increased risk exposures between the two-tiers is counterbalanced by the benefits derived from (a) liquidity pooling and (b) greater coordination between banks. In a related study Adams et al. (2010) simulate a simple model of network formation, where each bank can either transact directly with another bank or through a correspondent bank. The authors show that the model is capable of generating a network structure similar to that observed in the UK two-tier system that is driven only by the underlying pattern of payments and the structure of liquidity costs.

The structure of the system can also depend on the level of aggregation of transactions. Finger et al. (2012) using bank transactions from the Italian payments system find that when they use daily data the network is random, however, when they move to quarterly frequencies the structure becomes more asymmetric. Put differently, the network exhibits a more hierarchical structure at higher aggregation frequencies, though, still lower than those found for other national systems. They also emphasize that networks constructed at higher aggregation levels have properties that are more stable (less sensitive to the sampling period).

Analyzing the financial stability characteristics of the Colombian payments system, León et al. (2012) offer an example that demonstrates how important it is not to focus exclusively to institutions that are 'too big too fail' but also to those that are 'too interconnected too fail'. ${ }^{21}$ Focusing only on the former type of financial institutions in the case of Colombia would have ignored a small-size bank which, because of its high connectivity, imposed potentially a high risk of systemic failure.

\subsubsection{Cross-Border Transactions}

The study of topological properties is not exclusively restricted to national payments systems. A number of researchers have used the rich transactions data from the Bank of International Settlements to analyse the topology of the network of international payments. For example, Hattori and Suda (2007) use the dataset to analyse the evolution of the topology of the network of crossborder bank exposures and they find that it has become more tightly connected over time. The network's connectivity, degree and clustering coefficient have increased over time while the average path length has declined. Interestingly, systemic events such as the East Asia twin-crisis in 1997 and the LTCM collapse in 1998 did not disturb this trend. The authors comparing the advantages and disadvantages of these developments suggest that while this higher connectivity offers better opportunities for portfolio diversification and capital allocation it also enhances the likelihood of systemic risk and Haldane (2009) has suggested that over emphasis of the beneficial effects of increased connectivity led economists to under estimate the negative effects of the changes in the other network measures. The evolution of the international payments network is also studied by Garratt et al. (2011). They report that the network has changed drastically since the late 1980s. At that time when four financial centres formed one large supercluster the risk of contagion was quite high within its members but much

\footnotetext{
${ }^{21}$ For more on this distinction, see Saunders et al. (2009).
} 
lower globally. Since then the most influential centres have become significantly smaller but the risk of global contagion has significantly grown.

Von Peter (2007) identifies, in the cross-border international payment system, the same hub and spoke structure that characterizes most of the national payment systems. The author also finds that the relatively higher interconnected financial centres, and thus the more important from a systemic risk perspective, are not necessarily the largest in size. McGuire and Tarashev (2008) show how the BIS statistics can be used to identify potentially vulnerable financial centres and provide measurements of their exposure to shocks of various magnitudes.

\subsubsection{Other Financial Markets}

The majority of research on national financial systems is concentrated on the study of payments systems. Nevertheless, there are still a few applications of the network topology approach to other markets. Rørdam and Bech (2009) compare the networks of the money market and the payments system (Figure 8b) in Denmark. The payments network consists of banks' proprietary transactions and customer driven transactions while the money market network consists of overnight money market loans. The authors find that the structures of the two networks differ considerably. While activity in the payments network is dominated by two commercial banks that in the overnight market is more evenly distributed. In contrast to other studies they do not find that the degree distribution of the network is scale-free.

Bech and Atalay (2010) by concentrating on a sub-set of the transactions recorded by the Fedwire system are able to identify the network of the US federal funds market. These are overnight interbank loans that depend on the size of the reserves that the lender holds at the federal reserve system. In accordance with the results reported by Somaräki et al. (2007b) in relation to the total transactions in the Fedwire system, the authors find that the federal funds network exhibits the small-world phenomenon and that the distribution of the number of a bank's counterparties follows a fat-tailed distribution, whereby the vast majority of banks have a few counterparties and a small number of banks have many. However, they also report that the degree distribution of the federal funds market network is not necessarily best represented by a power law distribution.

A similar structure to the one for the federal funds market is reported by Markose et al. (2010) for the US market for Credit Default Swaps . The market is extremely concentrated with five banks dominating $(92 \%)$ the activity in these transactions.

\section{Moving Forward}

In this paper we have reviewed recent advances in financial economics in relation to the measurement of systemic risk. We have started by reviewing studies that apply traditional measures of risk to financial institutions. Such studies use balance-sheet data to gather information about a financial institution's risk exposure, market data to assess its performance and aggregate data for assigning weights that capture the relative contribution of the institution to systemic risk. Ultimately, the aim is to use reliable measures of contributions to systemic 
risk for developing pricing schemes that will offer incentives to financial institutions to internalize the externalities that they impose on the rest of the system. Acharya et al. (2009a) describe some interesting proposals aimed at achieving this last goal. ${ }^{22}$

The main focus of the review has been on studies that use network analysis paying special attention to those that apply complex analysis techniques. Applications of these techniques for the analysis and pricing of systemic risk has already provided significant benefits at least at the conceptual level but it also looks very promising from a practical point of view. ${ }^{23}$ The basic idea is that what matters for the evaluation of potential systemic consequences of a shock is not only the level of aggregate bilateral risk exposure within the financial system (for example the volume of interbank deposits) but also how this exposure is distributed within the system (the network of interbank deposits). As a first step complex network analysis can be used to trace the contagion effects of a particular shock throughout the system. But perhaps even more importantly it can be used to provide reliable measures for the exposure of the whole system to that shock.

At the theoretical level, significant progress has been made on both of these objectives. Considerable advances have also been made in relation to the first objective at the empirical level. In particular, the topological properties of a wide variety of financial systems around the world, both at the national level and at the level of cross-border transactions, have already been identified. Where improvement is still needed is in using the new tools for deriving practical measures of systemic risk. By practical we mean measures that regulators can use to design insurance pricing schemes for potentially catastrophic events.

The design of optimal schemes would take into account not only the aggregate risk exposure of a network to various kind of shocks but also the incentives that participating institution have to form one type of network over another. The recent work by Acemoglu et al. (2013) does exactly that at the theoretical level. Two issues that have restricted progress at the empirical level are lack of data and measurement problems. We have already discussed above the problem that researchers, who apply counterfactual analysis, face when they only have data for gross bilateral exposures. At this point, we focus on an alternative challenge that is related to the evaluation of systemic losses as a shock propagates throughout the system.

Clearly, if the losses are restricted to those directly related to the initial shock connectivity would not be a problem. In fact, the more connected a network is, the easier will be to diffuse the losses throughout the system without putting the system itself into danger. What this simplistic analysis ignores is the presence of market imperfections that are responsible for externalities related to (a) fire sales and market freezes (e.g., Acharya et al. (2011) and Diamond and Rajan (2011)), and (b) liquidity spirals (e.g., Brunnermeier and Pedersen (2009) and Garleanu and Pedersen (2007)). Earlier, we have reviewed a number of theoretical contributions that allow for these effects within the context of complex network analysis. In contrast, counterfactual and simulations

\footnotetext{
${ }^{22}$ When cross-border risk exposures are significant, as, for example, during the recent global financial crisis, it is also important to ensure there is international coordination among financial regulators; see Acharya et al. (2009b).

${ }^{23}$ Data limitations are a serious constraining factor both for researchers that aim to measure systemic risk and practioners who are interested in controlling it; see Cerutti et al. (2012).
} 
analyses that use actual financial networks as a starting point, usually employ an algorithm developed by Furfine (2003), that assigns an exogenously given parameter (LGD - loss-given-default) each round for these losses. Bridging the gap between theory and applied research in this particular area would add considerably to the attractiveness of the new methodologies.

Finally, some authors have suggested that it might be wise to identify clusters of financial institutions that potentially, because of either/both their size or/and high connectivity, impose disproportional higher risk on the rest of the system. The recent maximum likelihood methods developed by Čopič et al. (2009) for identifying such clusters in network structures might be a promising option.

Acknowledgement: We would like to acknowledge financial support from COST Action IS1104 "The EU in the new economic complex geography: models tools and policy analysis".

\section{References}

[1] Acemoglu D, Ozdaglar A, Tahbaz-Salehi A (2013) Systemic risk and stability in financial networks. NBER Working Paper 18727

[2] Acharya V, Gale D, Yorulmazer T (2011) Rollover risk and market freezes. Journal of Finance 66: 1175-1207

[3] Acharya V, Pedersen L, Philippon T, Richardson M (2009a) Regulating systemic risk. In Acharya V, Richardson M (eds) Restoring financial stability.Wiley, New Jersey, p. 283-303

[4] Acharya V, Pedersen L, Philippon T, Richardson M (2010) Measuring systemic risk. Unpublished Paper New York University

[5] Acharya V, Wachtel P, Walter I (2009b) International alignment of financial sector regulation. In Acharya V, Richardson M (eds) Restoring financial stability.Wiley, New Jersey, p. 365-376

[6] Adams M, Galbiati M, Giansante S (2010) Liquidity costs and tiering in large-value payment systems. Bank of England Working Paper 399

[7] Adrian T, Brunnermeier M (2011) CoVaR. NBER Working Paper 17454

[8] Allen F, Babus A (2009) Networks in finance. In Kleindorfer P, Wind Y, Gunther R (eds) The network challenge:strategy, profit, and risk in an interconnected world. Pearson Education, New Jersey, p. 367-382

[9] Allen F, Babus A (2010) Financial connections and systemic risk. NBER Working Paper 16177

[10] Allen F, Gale D (1998) Optimal financial crises. Journal of Finance 53: 1245-1284

[11] Allen F, Gale D (2000) Financial contagion. Journal of Political Economy 108: $1-33$

[12] Amundsen E, Arnt H (2005) Contagion risk in the Danish interbank market. Danmark Nationalbank Working Paper 2005-25 
[13] Anand K, Gai P, Kapadia S, Brennan S, Willison M (2013) A network model of financial system resilience. Journal of Economic Behavior and Organization 85: 219-235

[14] Anand K, Gai P, Marsili M (2012) Rollover risk, network structure and systemic financial crises. Journal of Economic Dynamics and Control 36: 1088-1100

[15] Anand K, Kirman A, Marsili M (2011) Epidemics of rules, information aggregation failure and market crashes. European Journal of Finance DOI: 10.1080/1351847X.2011.601872

[16] Angelini P, Maresca G, Russo D (1996) Systemic risk in the netting system. Journal of Banking and Finance 20: 853-868

[17] Aubuchon C, Wheelock D (2010) The geographic distribution and characteristics of U.S. bank failures, 2007-2010: Do bank failures still reflect local economic conditions? Federal Reserve Bank of St. Louis Review 92: $395-415$

[18] Babus A (2007) The formation of financial networks. Tinbergen institute Discussion Paper 06-093

[19] Battiston S, Delli Gatti D, Gallegati M, Greenwald B, Stiglitz J (2007) Credit chains and bankruptcy propagation in production networks. Journal of Economic Dynamics and Control 31: 2061-2084

[20] Battiston S, Puliga M, Kaushik R, Tasca P, Caldarelli G (2012) DebtRank: too central to fail? Financial networks, the FED and systemic risk. Scientific Reports 2: 541 doi: 10.1038/srep00541

[21] Bech M, Atalay E (2010) The topology of the federal funds market. Physica A 389: 5223-5246

[22] Becher C, Millard S, Somaräki K (2008) The network topology of CHAPS Sterling. Bank of England Working Paper 355

[23] Bhattacharya S, Gale D (1987) Preference shocks, liquidity and central bank policy. in Barnett W, Singleton K (eds) New approaches to monetary economics. Cambridge University Press, Cambridge, p.69-88

[24] Billio M, Getmansky M, Lo A, Pelizzon L (2012) Econometric measures of connectedness and systemic risk in the finance and insurance sectors. Journal of Financial Economics 104: 535-559

[25] Bitzer D, DeMarzo P (1992) Sequential banking. Journal of Political Economy 100: 41-61

[26] Boss M, Elsinger H, Summer M, Thurner S (2004) The network topology of the interbank market. Quantitative Finance 4: 677-684

[27] Blavarg M, Nimander P (2002) Inter-bank exposures and systemic risk. Sveriges Riksbank Economic Review 2/2002 
[28] Brunnermeier M, Oehmke M (2012) Bubbles, Financial Crises, and Systemic Risk. Princeton University Research Paper 47-2012

[29] Brunnermeier M, Pedersen L (2009) Market liquidity and funding liquidity. Review of Financial Studies 22: 2201-2238

[30] Caballero R, Simsek A (2009) Complexity and financial panics. NBER Working Paper 14997

[31] Castiliognesi F, Navarro N (2007) Optimal fragile financial networks. Tilburg University Discussion Paper 2007-100

[32] Castrén O, Kavonius I (2009) Balance sheet interlinkages and macrofinancial risk analysis of the euro area. ECB Working Paper 1124

[33] Castrén O, Rancan M (2013) Macro-networks: an application to the euro area financial accounts. ECB Working Paper 1510

[34] Cerutti E, Claessens S, McGuire P (2012) Systemic Risks in Global Banking: What Available Data Can Tell Us and What More Data are Needed? NBER Working Paper 18531

[35] Cifuentes R, Ferrucci G, Shin H (2005) Liquidity risk and contagion. Journal of the European Economic Association 3: 556-566

[36] Čopič J, Jackson M, Kirman A (2009) Identifying community structures from network data via maximum likelihood methods. B.E. Journal of Theoretical Economics, BEP 9

[37] Cossin D, Schellhorn H (2007) Credit risk in a network economy. Management Science 53: 1604-1617

[38] Da Cruz J, Lind P (2012) The dynamics of financial stability in complex networks. European Physical Journal B 85: 256

[39] De Jonghe (2010) Back to the basics in banking? A micro-analysis of banking system stability. Journal of Financial Intermediation 19: 387-417

[40] Degryse H, Elahi M, Penas M (2009) Cross-border exposures and financial contagion. European Banking Center Discussion Paper 2009-02

[41] Degryse H, Nguyen G (2007) Interbank exposures: an empirical examination of systemic risk in the Belgian banking system. Journal of International Central Banking 3: 123-171

[42] Diamond D, Dybvig P (1983) Bank runs, deposit insurance and liquidity. Journal of Political Economy 91: 401-419

[43] Diamond D, Rajan R (2011) Fear of fire sales, illiquidity seeking, and credit freezes. Quarterly Journal of Economics 126: 557-591

[44] Eisenberg L, Noe T (2001) Systemic risk in financial systems. Management Science 47: 236-249

[45] Elliott M, Golub B, Jackson M (2013) Financial networks and contagion. Available at SSRN: http://ssrn.com/abstract $=2175056$ 
[46] Elsinger H, Lehar A, Summer M (2006) Risk assessments for banking systems. Management Science 52: 1301-1314

[47] Embree L, Roberts T (2009) Network analysis and Canada's Large Value Transfer System. Bank of Canada Discussion Paper 2009-13

[48] Erdös P, Rényi A (1959) On random graphs. Publicationes Mathematicae Debrecen 6: 220-297

[49] European Central Bank (2007) Conference proceedings of the fourth joint central bank research conference, 8-9 November 2005. ECB, Frankfurt

[50] Finger K, Fricke D, Lux T (2012) : Network analysis of the e-MID overnight money market: the informational value of different aggregation levels for intrinsic dynamic processes. Kiel Working Paper 1782

[51] Furfine C (2003) Interbank exposures: quantifying the risk of contagion. Journal of Money, Credit and Banking 35: 111-128

[52] Gai P, Kapadia S (2010) Contagion in financial networks. Proceedings of the Royal Society A 466: 2401-2423

[53] Garleanu N, Pedersen L (2007) Liquidity and risk management. American Economic Review Papers and Proceedings 97: 193-197

[54] Garratt R, Mahadeva L, Svirydzenka S (2011) Mapping systemic risk in the international banking network. Bank of England Working Paper 413

[55] Gauthier C, Lehar A, Souissi M (2009) Macroprudential capital requirements and systemic risk. Unpublished Paper Bank of Canada

[56] Giglio S (2011) Credit default swap spreads and systemic financial risk. Unpublished Paper Harvard University

[57] Goyal S (2009) Connections: an introduction to the economics of networks. Princeton University Press, Princeton

[58] Gray D, Merton R, Bodie Z (2008) New framework for measuring and managing macrofinancial risk and financial stability. Harvard Business School Working Paper 09-015

[59] Haldane A (2009) Rethinking the financial network. Speech delivered at the Financial Student Association, Amsterdam

[60] Haldane A, May R (2011) Systemic risk in banking ecosystems. Nature 469: $351-355$

[61] Hartmann P, Straetmans S, de Vries C (2005) Banking system stability: a cross-Atlantic perspective. NBER Working Paper 11698

[62] Hattori M, Suda Y (2007) Developments in a cross-border bank exposure "network". Bank of Japan Working Paper 07-E-21

[63] Huang X, Zhou H, Zhu H (2012) Systemic risk contributions. Journal of Financial Services Research 42: 55-83 
[64] Inaoka H, Ninomiya T, Taniguchi K, Shimizu T, Takayasu H (2004) Fractal Network derived from banking transactions: an analysis of network structures formed by financial institutions. Bank of Japan Working Paper 04-E-04

[65] Iori G, Jafarey S, Padilla F (2006) Systemic risk on the interbank market. Journal of Economic Behavior and Organization 61: 525-542

[66] Jackson M (2008) Social and economic networks. Princeton University Press, Princeton

[67] Kiyotaki N, Moore J (2004) Credit chains. University of Edinburgh ESE Discussion Paper 118

[68] Lagunoff R, Schreft L (2001) A model of financial fragility. Journal of Economic Theory 99: 220-264

[69] Lehar A (2005) Measuring systemic risk: a risk management approach. Journal of Banking and Finance 29: 853-864

[70] Leitner Y (2005) Financial networks: contagion, commitment, and private sector bailouts. Journal of Finance 60: 2925-2953

[71] Lenzu S, Tedeschi G (2012) Systemic risk on different interbank network topologies. Physica A 391: 4331-4341

[72] León C, Machado C, Cepeda F, Sarmiento M (2012) Systemic risk in large value payment systems in Colombia: a network topology and payments simulation approach. In Hellqvist M, Laine T (eds) Diagnostics for the financial markets: computational studies of payment system. Edita Prima Oy, Helsinki, p. 267-313

[73] Lublóy A (2005) Domino effect in the Hungarian interbank market. Kozgazdasagi Szemle (Economic Review) 42: 377-401

[74] Lublóy A (2006) Topology of the Hungarian large-value transfer system. Magyar Nemzeti Bank Occasional Paper 57

[75] Markellof R, Warner G, Wollin E (2012) Modeling systemic risk to the financial system. MITRE Corporation Technical Paper 12-1870

[76] Markose S, Giansante S, Gatkowski M and Shaghaghi A (2010) Too interconnected to fail: financial contagion and systemic risk in network model of CDS and other credit enhancement obligations of US banks. University of Essex Discussion Paper 683

[77] May R, Arinaminpathy N (2010) Systemic risk: the dynamics of model banking systems. Interface: Journal of the Royal Society 7, 823-838

[78] May R, Levin S, Sugihara G (2008) Ecology for bankers. Nature 451: 893-895

[79] McGuire P, Tarashev N (2008) Global monitoring with the BIS international banking statistics. BIS Working Paper 244 
[80] Mistrulli P (2011) Assessing financial contagion in the interbank market: maximum entropy versus observed interbank lending patterns. Journal of Banking and Finance 35: 1114-1127

[81] Montagna M, Lux T (2013) Hubs and resilience: towards more realistic models of the interbank markets. Kiel Working Paper 1826

[82] Nier E, Yang J, Yorulmazer T, Alentorn A (2007) Network models and financial stability. Journal of Economic Dynamics and Control 31: 20332060

[83] Pröpper M, van Lelyveld I, Heijmans R (2012) Network dynamics of TOP payments. In Hellqvist M, Laine T (eds) Diagnostics for the financial markets: computational studies of payment system. Edita Prima Oy, Helsinki, p. $235-266$

[84] Rørdam K, Bech M (2009) The topology of Danish interbank money flows. Banks and Bank Systems 4: 48-65

[85] Rochet J-C, Tirole J (1996) Interbank lending and systemic risk. Journal of Money, Credit, and Banking 28: 733-762

[86] Saunders A, Smith R, Walter I (2009) Enhanced regulation of large complex financial institutions. In Acharya V, Richardson M (eds) Restoring financial stability. Wiley, New Jersey, p. 139-156

[87] Schweitzer F, Fagiolo G, Sornette D, Vega-Redondo F, Vespignani A, White D (2009) Economic networks: the new challenges. Science 325: $422-425$

[88] Segoviano M, Goodhart C (2009) Banking stability measures. IMF Discussion Paper 627

[89] Sheldon G, Mauer M (1998) Interbank lending and systemic risk: an empirical analysis of Switzerland. Swiss Journal of Economics and Statistics 134: $685-704$

[90] Sokolov A, Webster R, Melatos A, Kieu T (2012) Loan and nonloan flows in the Australian interbank network. Physica A 391: 2867-2882

[91] Somaräki K, Bech M, Arnold J, Glass R, Beylerer W (2007a) The topology of interbank payment flows. Physica A 379: 317-333

[92] Soramäki K, Beyeler W, Bech M, Glass R (2007b) New approaches for payment system simulation research. In. Leinonen H (ed) Simulation studies of liquidity needs, risks and efficiency in payment networks. Edita Prima Oy, Helsinki, p.15-39

[93] Tarashev N, Borio C, Tsatsaronis K (2010) Allocating systemic risk to individual institutions; methodology and policy applications. BIS Working Paper 308

[94] Teteryatnikova M (2012) Systemic Risk in Banking Networks: Advantages of "Tiered" Banking Systems. University of Vienna Working Paper 1203 
[95] Upper C (2007) Using counterfactual simulations to assess the danger of contagion in interbank markets, BIS Working Paper 234

[96] Upper C, Worms A (2004) Estimating bilateral exposures in the German interbank market: Is there a danger of contagion? European Economic Review 48: 827-849

[97] Van Lelyveld I, Liedorp F (2006) Interbank contagion in the Dutch banking sector: a sensitivity analysis. International Journal of Central Banking 2: $99-134$

[98] Varela L-M, Rotundo G, Ausloos M, Carrete J (2013) Complex networks analysis in socioeconomic models. This volume.

[99] Vega-Redondo F (2007) Complex social networks. Cambridge University Press, Cambridge

[100] Von Peter G, (2007) International banking centres: a network perspective. BIS Quarterly Review Working Paper. http://dx.doi.org/10.2139/ssrn.1075205

[101] Wells S (2004) Financial interlinkages in the United Kingdom's interbank market and the risk of contagion. Bank of England Working Paper 230

[102] Wong A, Fong T (2010) An analysis of the interconnectivity among the Asia-Pacific Economies. Unpublished Paper Hong Kong Monetary Authority 